\title{
Documentation of Ethnoveterinary Knowledge among the Somali Pastoral Community in Eastern Part of Ethiopia: With Special Emphasis on Herbal Medicine for Livestock Health
}

Biressaw Serda*

College of Veterinary Medicine, Haramaya University, PO Box 138, Dire Dawa, Ethiopia

*Corresponding author: Biressaw Serda, College of Veterinary Medicine, Haramaya University, PO Box 138, Dire Dawa, Ethiopia, Tel: +251911052265; Fax:+251255530325; E-mail: biressawserda2011@gmail.com

Received September 10, 2017; Accepted November 28, 2017; Published November 29, 2017

\section{Retraction Note:}

The article entitled "Documentation of Ethnoveterinary Knowledge among the Somali Pastoral Community in Eastern Part of Ethiopia: With Special Emphasis on Herbal Medicine for Livestock Health," has been accepted for publication in the Journal of Veterinary Science \& Technology considering the statements provided in the article as personal opinion of the author which was found not having any conflict or biasness towards anything. As the article was a perspective one, information provided by the author was considered as an opinion to be expressed through publication. Publisher took decision to make the article online solely based on the reviewers suggestion which considered the article not but a personal opinion of the author. However, it is found that the author have some personal concerns and issues, therefore, being retracted from the journal. 